\title{
PENGENDALIAN PERSEDIAAN OBAT GENERIK DENGAN METODE MMSL (Minimum-Maximum Stock Level) DI UNIT FARMASI RUMAH SAKIT ISLAM SURABAYA
}

\author{
Ayu Kumalasari*, Thinni Nurul Rochmah* \\ *Fakultas Kesehatan Masyarakat, Universitas Airlangga, Surabaya \\ Email:ayukkumalasari@gmail.com
}

\begin{abstract}
ABSTRAK
Rumah Sakit merupakan organisasi yang padat karya dan padat modal, sehingga dalam pengelolaannya harus efektif dan efisien.Salah satu yang harus dikelolah dengan baik adalah logistik obat.Di Rumah Sakit Islam Surabaya terdapat kejadian stockout obat pada jenis obat generik dengan rata-rata kejadian sebesar $56 \%$ pada bulan Juli-Desember tahun 2015.Hal ini disebabkan karena belum ada metode perencanaan dan pengendalian persediaan yang diterapkan.Tujuan penelitian ini adalah untuk melakukan perencanaan dengan melakukan analisis berdasarkan tingkat pemakaian obat dan melakukan peramalan dengan menggunakan metode least square dan pengendalian persediaan dengan menggunakan metode MMSL. Penelitian dilakukan di Unit Farmasi Rumah Sakit Islam Surabaya dengan rancangan cross sectional, mengggunakan metode deskriptif dengan pendekatan kuantitatif.Penelitian dengan menggunakan data sekunder pemakaian obat pada Tahun 2015.Variabel terikat adalah data pemakaian riil obat.Variabel bebas adalah metode perencanaan dan pengendalian persediaan yang digunakan. Hasil penelitian diperoleh bahwa di Rumah Sakit Islam Surabaya belum ada metode perencanaan dan pengendalian persediaan tertentu yang digunakan.Klasifikasi obat generik berdasarkan analisis tingkat pemakaian diperoleh hasil 28 jenis obat termasuk dalam kategori fast moving.Hasil peramalan kebutuhan Tahun 2016 akan digunakan untuk melakukan pengendalian persediaan. Hasil perhitungan metode MMSL akan diperoleh nilai stok minimum dan maksimum persediaan obat. Hasil penelitian didapatkan nilai pengendalian persediaan untuk obat generik dengan metode MMSL.Didapatkan nilai stok minimum dan maksimum obat generik serta didapatkan nilai jumlah pemesanan kembali masing-masing obat generik dengan kategori fast moving.
\end{abstract}

Kata Kunci : Analisis Berdasarkan Pemakaian, Least Square Method, MMSL

\section{ABSTRACT}

Hospital is a labor-intensive and capital-intensive organization, so the management should be effective and efficient. One that should be managed properly is the logistic of drugs. The reports from July-December 2015 show that the stockout of generic drugs occur in Islamic Hospital of Surabaya with an average incidence of 56\%, because there is no planning and inventory control methods are applied. The aim of this research is to make a plan based on the level of drug usage and forecasting analysis by using the least squares method and inventory control using MMSL method. This research was conducted in Pharmacy Unit Islamic Hospital of Surabaya with cross-sectional design, using descriptive method with quantitative approach. The secondary data was from the drug usage in 2015. The dependent variable was the real drug consumption data. The independent variable was the application of planning and inventory control methods. The result of this research shows 
that Islamic Hospital of Surabaya has not applied the planning and controlling methods of certain supplies. The classification of generic drugs based on the analysis of the consumption levels indicates that 28 types of drugs included in the category of fast moving. The forecasting results in 2016 will be used to perform inventory control. The results of the MMSL method calculation indicate the minimum and maximum value of the stock of drug supplies. The conclusion of this research is the value of inventory control for generic drugs with MMSL method. It has minimum and maximum stock value and reorder point level for generik drugs in the category of fast moving.

Key Words : Analysis By Consumption, Least Square Method, MMSL

\section{PENDAHULUAN}

Manajemen logistik merupakan hal yang sangat penting bagi rumah sakit untuk mengelola persediaan logistik rumah sakit.Obat termasuk dalam salah satu kategori logistik yang harus dikelola dengan baik dalam manajemen logistik.Pengelolaan persediaan obat diperlukan karena jika dibandingkan dengan persediaan pada umumnya, obat memiliki beberapa kekhususan.Pertama, persediaan obat memiliki umur yang terbatas dan mudah rusak.Kedua, persediaan obat membutuhkan biaya yang sangat besar. Persediaan obat yang terlalu besar atau kecil akan membuat rumah sakit mengalami kerugian. Kerugian tersebut dapat berupa biaya persediaan obat yang membesar serta terganggunya kelancaran pelayanan kesehatan di rumah sakit.

Pelayanan farmasi merupakan pelayanan penunjang sekaligus merupakan revenue center utama. Hal tersebut mengingat bahwa lebih dari $90 \%$ pelayanan kesehatan di rumah sakit menggunakan perbekalan farmasi (obat-obatan, bahan kimia, bahan radiologi, bahan habis pakai alat kesehatan, alat kedokteran dan gas medik), dan $50 \%$ dari seluruh pemasukan rumah sakit berasal dari pengelolaan perbekalan farmasi. Dikarenakan hal tersebut, jika masalah perbekalan farmasi tidak dikelola secara cermat dan penuh tanggung jawab maka dapat diprediksi bahwa pendapatan rumah sakit akan mengalami penurunan (Suciati et al, 2006).

Berdasarkan studi pendahuluan yang dilakukan di Rumah Sakit Islam Surabaya terhadap keadaan persediaan obat generik, terjadi stockout obat dari bulan JuliDesember 2015, rata-rata kejadian stockout dari 6 bulan tersebut sebesar $56 \%$. Adanya kejadian stockout tersebut menunjukkan perencanaan dan pengendalian persediaan yang belum efektif sehingga akan mempengaruhi ketersediaan obat dan perputaran penjualan obat di rumah sakit.

Tujuan penelitian ini yaitu melakukan analisis berdasarkan tingkat pemakaian obat, menghtiung nilai forecasting berdasarkan least square method dan pengendalian persediaan dengan metode MMSL di Unit Farmasi Rumah Sakit Islam Surabaya.Adapun manfaat penelitian yaitu dapat dijadikan sebagai pertimbangan untuk rumah sakit dalam melakukan perencaan dan pengendalian persediaan agar ketersediaan obat dapat dikontrol dengan baik.

\section{METODE}

Jenis penelitian ini termasuk dalam penelitian deskriptif dengan pendekatan kuantitatif.Merupakan penelitian observasional.Sedangkan ditinjau dari waktu, penelitian ini termasuk penelitian cross sectional, yaitu pengamatan dilakukan sekali dalam saat tertentu saja.Unit analisis dalam penelitian ini yaitu Unit Farmasi Rumah Sakit Islam Surabaya.Sumber Informasi diperoleh dari hasil wawancara dengan Kepala Unit Farmasi dan petugas gudang logistik Rumah Sakit Islam Surabaya dan data 
sekunder pemakaian obat tahun 2015 dan 2016.

\section{HASIL DAN PEMBAHASAN}

Berdasarkan hasil wawancara dengan Kepala Unit Farmasi dan petugas gudang logistik didapatkan hasil belum ada metode perencanaan yang digunakan untuk menentukan kebutuhan obat.Keduanya menyebutkan bahwa penentuan kebutuhan obat didasarkan atas perkiraan penggunaan obat periode sebelumnya tanpa perhitungan menggunakan metode peramalan tertentu.Kedua narasumber menyebutkan pemesanan obat dilakukan setiap hari senin dan kamis untuk item obat yang berbeda-beda tergantung dari kondisi sisa obat.

Hasil wawancara untuk metode pengendalian persediaan obat yang digunakan di Rumah Sakit Islam Surabaya didapatkan hasil narasumber menyebutkan belum terdapat metode tertentu yang digunakan untuk melakukan pengendalian persediaan obat.Hal tersebut dikarenakan terkadang sisa obat dengan kebutuhan selisih sedikit. Kedua narasumber menyebutkan belum begitu memahami apa yang dimaksud dengan metode pengendalian persediaan obat.

\section{Analisis Tingkat Pemakaian Obat}

Berdasarkan analisis tingkat pemakaian obat generik pada Tahun 2015, dari 148 jenis obat generik yang diteliti diperoleh hasil 28 obat termasuk dalam kategori pemakaian fast moving.Obat tersebut memiliki nilai komulatif pemakaian dengan persen (\%) komulatifnya 0$70 \%$.Jenis obat tersebut disajikan dalam tabel sebagai berikut :

Tabel 1.1 Hasil Analisis Tingkat Pemakaian Obat

\begin{tabular}{|l|l|l|l|}
\hline No & Nama Obat & $\begin{array}{l}\text { Jumlah } \\
\text { Pakai }\end{array}$ & $\%$ \\
\hline 1 & Metformin $500 \mathrm{mg} /$ & 523.883 & 17 \\
\hline
\end{tabular}

\begin{tabular}{|c|c|c|c|}
\hline & 100 & & \\
\hline 2 & $\begin{array}{l}\text { Amlodipine } 10 \mathrm{mg} / \\
30^{\prime}\end{array}$ & 139.852 & 21 \\
\hline 3 & $\begin{array}{l}\text { Amlodipine } 5 \mathrm{mg} / \\
30^{\prime}\end{array}$ & 125.181 & 25 \\
\hline 4 & Simvastatin $10 \mathrm{mg}$ & 113.006 & 28 \\
\hline 5 & Glibenclamide & 106.443 & 32 \\
\hline 6 & Glimepiride $3 \mathrm{mg}$ & 104.906 & 35 \\
\hline 7 & Paracetamol tab & 97.193 & 38 \\
\hline 8 & Furosemide 40 & 75.669 & 40 \\
\hline 9 & $\begin{array}{l}\text { Asam mefenamat } \\
500\end{array}$ & 75.445 & 43 \\
\hline 10 & Bisoprolol fumrt & 65.498 & 45 \\
\hline 11 & Ranitidin 150 & 65.338 & 45 \\
\hline 12 & $\begin{array}{ll}\text { Pyrazinamid } & 500 \\
\text { mg }\end{array}$ & 58.056 & 47 \\
\hline 13 & Amitriptyline 25 & 57.718 & 48 \\
\hline 14 & Meloxicam $15 \mathrm{mg}$ & 53.892 & 50 \\
\hline 15 & Omeprazol & 52.352 & 52 \\
\hline 16 & Ambroxol $30 \mathrm{mg}$ & 50.842 & 53 \\
\hline 17 & Natrium diclofenac & 50.038 & 55 \\
\hline 18 & $\begin{array}{ll}\text { Spironolacton } & 25 \\
\mathrm{mg}\end{array}$ & 46.073 & 57 \\
\hline 19 & Salbutamol $2 \mathrm{mg}$ & 45.922 & 58 \\
\hline 20 & Allopurinol 100 & 45.747 & 59 \\
\hline 21 & $\begin{array}{l}\text { Methylprednisolon } \\
4\end{array}$ & 42.481 & 61 \\
\hline 22 & Lisinopril $10 \mathrm{mg}$ & 42.375 & 62 \\
\hline 23 & Cefixim $100 \mathrm{mg} / 30$ & 39.047 & 63 \\
\hline 24 & Domperidon & 38.832 & 65 \\
\hline 25 & $\begin{array}{l}\text { Amoxicillin } 500 \\
\mathrm{mg}\end{array}$ & 36.275 & 67 \\
\hline 26 & Glimepiride $2 \mathrm{mg}$ & 35.978 & 68 \\
\hline 27 & Candesartan 16 & 35.832 & 69 \\
\hline 28 & $\begin{array}{l}\text { Antacida doen } \\
\text { tablet }\end{array}$ & 35.370 & 70 \\
\hline
\end{tabular}

Berdasarkan Tabel 1.1 dapat diketahui tingkat pemakaian obat terbanyak terdapat pada jenis obat Metformin $500 \mathrm{mg} / 100$ dan tingkat pemakaian terendah terdapat pada jenis obat Antacida doen tablet.

\section{Peramalan Kebutuhan Obat}

Nilai peramalan obat untuk Tahun 2016 diperoleh dari data pemakaian obat Tahun 2015, dihitung dengan menggunakan metode least square.Peramalan/forecasting dengan metode least square menggunakan persamaan linier:

$\mathrm{Y}^{\prime} \quad=\mathrm{a}+\mathrm{b}(\mathrm{x})$

Nilai a dan b dicari dengan melibatkan nilai $\mathrm{x}$ ( sebagai variabel independent) 
penentuan nilai $\mathrm{x}$ untuk mencari $\mathrm{a}$ dan $\mathrm{b}$ digunakan alternative dengan memberikan skor atau kode. Terdapat pembagian data menjadi genap dan ganjil, dalam penelitian ini data yang ada memiliki periode genap yaitu 12 bulan sehingga menggunakan skor genap dimulai dari -11 hingga 11 .

Nilai a dirumuskan, $\mathrm{a}=\Sigma \mathrm{Y} / \mathrm{n}$.

Nilai $\mathrm{b}$ dirumuskan, $\mathrm{b}=\Sigma \mathrm{x} Y / \Sigma \mathrm{x}^{2}$.

Pada perencanaan peramalan dan pengendalian persediaan dalam penelitian ini akan diambil 5 sampel dari obat generik dengan kategori pemakaian fast moving untuk dihitung nilai peramalan dan pengendalian persediaan obat, agar ketersediaan obat sesuai dengan kebutuhan. Perhitungan nilai peramalan obat untuk 5 sampel obat generik tersebut didapatkan hasil sebagai berikut:

1. metformin $500 \mathrm{mg} / 100$

Tabel.2.1 Perhtiungan nilai koefisien a dan b obat generik Metformin 500 mg/100

\begin{tabular}{lrrrr}
\hline $\begin{array}{c}\text { Tahun } \\
\text { 2015 }\end{array}$ & $\mathbf{x}$ & $\begin{array}{c}\text { Pakai } \\
\mathbf{2 0 1 5}\end{array}$ & $\mathbf{x i}^{\mathbf{2}}$ & \multicolumn{1}{c}{ xiyi } \\
\hline Jan & -11 & 33.661 & 121 & -370.271 \\
Feb & -9 & 35.804 & 81 & -322.236 \\
Mar & -7 & 36.715 & 49 & -257.005 \\
Apr & -5 & 28.432 & 25 & -142.160 \\
Mei & -3 & 26.352 & 9 & -79.596 \\
Jun & -1 & 30.448 & 1 & -30.448 \\
Jul & 1 & 20.638 & 1 & 20.638 \\
Agst & 3 & 27.977 & 9 & 83.931 \\
Sept & 5 & 37.498 & 25 & 187.490 \\
Okt & 7 & 45.874 & 49 & 321.118 \\
Nov & 9 & 42.151 & 81 & 379.359 \\
Des & 11 & 42.708 & 121 & 469.788 \\
\hline Total & 0 & 408.258 & 572 & 261.148 \\
\hline
\end{tabular}

$$
\begin{aligned}
\mathrm{a} & =\Sigma \mathrm{Y} / \mathrm{n} \\
& =408.258 / 12 \\
= & 34.021,5 \\
\mathrm{~b} & =\sum \mathrm{xy} / \sum \mathrm{x}^{2} . \\
& =261.148 / 572 \\
= & 456,55
\end{aligned}
$$

Nilai prediksi kebutuhan diperoleh dari rumus:

$\mathrm{Y}=\mathrm{a}+\mathrm{b}(\mathrm{x})$

Berikut hasil perhitungan kebutuhan obat generik Metformin $500 \mathrm{mg} / 100$ Tahun 2015 di Rumah Sakit Islam Surabaya:
Tabel 2.2 Peramalan Kebutuhan Obat Metformin 500 mg/100 Tahun 2016 di RS Islam Surabaya

\begin{tabular}{lccrr}
\hline $\begin{array}{c}\text { Tahun } \\
\text { 2016 }\end{array}$ & x & $\begin{array}{c}\text { Nilai } \\
\mathbf{a}\end{array}$ & $\begin{array}{c}\text { Nilai } \\
\text { b }\end{array}$ & $\begin{array}{c}\text { Peramalan } \\
\text { kebutuhan }\end{array}$ \\
\hline Jan & 13 & $34.021,5$ & 456,5 & 39.957 \\
Feb & 14 & $34.021,5$ & 456,5 & 40.413 \\
Mar & 15 & $34.021,5$ & 456,5 & 40.870 \\
Apr & 16 & $34.021,5$ & 456,5 & 41.326 \\
Mei & 17 & $34.021,5$ & 456,5 & 41.783 \\
Jun & 18 & $34.021,5$ & 456,5 & 42.239 \\
Jul & 19 & $34.021,5$ & 456,5 & 42.696 \\
Agst & 20 & $34.021,5$ & 456,5 & 43.153 \\
Sept & 21 & $34.021,5$ & 456,5 & 43.609 \\
Okt & 22 & $34.021,5$ & 456,5 & 44.066 \\
Nov & 23 & $34.021,5$ & 456,5 & 44.522 \\
Des & 24 & $34.021,5$ & 456,5 & 44.979 \\
\hline \multicolumn{1}{c}{ Total } & \multicolumn{3}{c}{} & 509.613 \\
\hline
\end{tabular}

Berdasarkan Tabel 2.2 diatas diperoleh angka peramalan/prediksi kebutuhan obat Metformin $500 \mathrm{mg} / 100$ sebesar 509.613 tablet untuk Tahun 2016.

2. Amlodipine $10 \mathrm{mg} / 30$

Tabel. 2.3 Perhtiungan nilai koefisien a dan b obat generik Amlodipine $10 \mathrm{mg} / 30$

\begin{tabular}{lrrrr}
\hline $\begin{array}{c}\text { Tahun } \\
\text { 2015 }\end{array}$ & \multicolumn{1}{c}{$\mathbf{x}$} & \multicolumn{1}{c}{$\begin{array}{c}\text { Pakai } \\
\mathbf{2 0 1 5}\end{array}$} & \multicolumn{1}{c}{$\mathbf{x i}^{2}$} & \multicolumn{1}{c}{ xiyi } \\
\hline Jan & -11 & 10.308 & 121 & -113.388 \\
Feb & -9 & 8.563 & 81 & -77.067 \\
Mar & -7 & 9.928 & 49 & -69.496 \\
Apr & -5 & 9.917 & 25 & -49.585 \\
Mei & -3 & 10.822 & 9 & -32.466 \\
Jun & -1 & 9.799 & 1 & -9.799 \\
Jul & 1 & 8.656 & 1 & 8.656 \\
Agst & 3 & 10.027 & 9 & 30.081 \\
Sept & 5 & 10.012 & 25 & 50.060 \\
Okt & 7 & 10.866 & 49 & 76.052 \\
Nov & 9 & 10.837 & 81 & 97.533 \\
Des & 11 & 9.415 & 121 & 103.565 \\
\hline Total & 0 & 119.170 & 572 & 14.146 \\
\hline a $=\sum \mathrm{Y} / \mathrm{n}$ & & & \\
$=119.170 / 12$ & & & \\
$=9930,83$ & & & \\
b & $=\sum x y / \sum \mathrm{x}^{2}$. & & & \\
$=14.146 / 572$ & & & \\
$=25,73$ & & &
\end{tabular}

Nilai prediksi kebutuhan diperoleh dari rumus:

$\mathrm{Y}=\mathrm{a}+\mathrm{b}(\mathrm{x})$ 
Berikut hasil perhitungan kebutuhan obat generikAmlodipine 10 mg/30 Tahun 2015 di Rumah Sakit Islam Surabaya:

Tabel 2.4 Peramalan Kebutuhan Obat Amlodipine 10 mg/30 Tahun 2016 di RS Islam Surabaya

\begin{tabular}{lccrr}
\hline $\begin{array}{c}\text { Tahun } \\
\text { 2016 }\end{array}$ & $\mathbf{x}$ & Nilai a & Nilai b & $\begin{array}{r}\text { Peramalan } \\
\text { Kebutuhan }\end{array}$ \\
\hline Jan & 13 & $9.930,8$ & 25,73 & 10.256 \\
Feb & 14 & $9.930,8$ & 25,73 & 10.281 \\
Mar & 15 & $9.930,8$ & 25,73 & 10.306 \\
Apr & 16 & $9.930,8$ & 25,73 & 10.331 \\
Mei & 17 & $9.930,8$ & 25,73 & 10.356 \\
Jun & 18 & $9.930,8$ & 25,73 & 10.381 \\
Jul & 19 & $9.930,8$ & 25,73 & 10.406 \\
Agst & 20 & $9.930,8$ & 25,73 & 10.431 \\
Sept & 21 & $9.930,8$ & 25,73 & 10.457 \\
Okt & 22 & $9.930,8$ & 25,73 & 10.481 \\
Nov & 23 & $9.930,8$ & 25,73 & 10.506 \\
Des & 24 & $9.930,8$ & 25,73 & 10.531 \\
\hline Total & 0 & & & 124.719 \\
\hline
\end{tabular}

Berdasarkan Tabel 2.4 diatas diperoleh angka peramalan/prediksi kebutuhan obat Amlodipine 10mg/30 sebesar 124.719 tablet untuk Tahun 2016.

3. Amlodipine $5 \mathrm{mg} / 30^{\prime}$

Tabel. 2.5 Perhtiungan nilai koefisien a dan b obat generik Amlodipine $5 \mathrm{mg} / 30$

\begin{tabular}{lrrrr}
\hline $\begin{array}{c}\text { Tahun } \\
\mathbf{2 0 1 5}\end{array}$ & \multicolumn{1}{c}{$\mathbf{x}$} & $\begin{array}{c}\text { Pakai } \\
\mathbf{2 0 1 5}\end{array}$ & \multicolumn{1}{c}{$\mathbf{x i}^{\mathbf{2}}$} & \multicolumn{1}{c}{$\mathbf{x i y i}$} \\
\hline Jan & -11 & 7.463 & 121 & -82.093 \\
Feb & -9 & 6.653 & 81 & -59.877 \\
Mar & -7 & 7.204 & 49 & -50.428 \\
Apr & -5 & 6.706 & 25 & -33.530 \\
Mei & -3 & 5.482 & 9 & -16.284 \\
Jun & -1 & 5.889 & 1 & -5.889 \\
Jul & 1 & 6.409 & 1 & 6.409 \\
Agst & 3 & 9.197 & 9 & 27.591 \\
Sept & 5 & 10.012 & 25 & 50.060 \\
Okt & 7 & 9.840 & 49 & 68.880 \\
Nov & 9 & 12.787 & 81 & 115.083 \\
Des & 11 & 8.665 & 121 & 95.315 \\
\hline Total & 0 & 96.307 & 572 & 115.237 \\
\hline
\end{tabular}

$$
\begin{aligned}
\mathrm{a} & =\Sigma \mathrm{Y} / \mathrm{n} \\
& =96.307 / 12 \\
& =8.025,58 \\
\mathrm{~b} & =\Sigma \mathrm{xy} / \Sigma \mathrm{x}^{2} . \\
& =21.552 .994 / 572 \\
& =201,46
\end{aligned}
$$

Nilai prediksi kebutuhan diperoleh dari rumus:

$\mathrm{Y}=\mathrm{a}+\mathrm{b}(\mathrm{x})$

Berikut hasil perhitungan kebutuhan obat generikAmlodipine 5 mg/30 Tahun 2015 di Rumah Sakit Islam Surabaya:

Tabel 2.6 Peramalan Kebutuhan Obat Amlodipine 5 mg/30 Tahun 2016 di RS Islam Surabaya

\begin{tabular}{lccrr}
\hline $\begin{array}{c}\text { Tahun } \\
\text { 2016 }\end{array}$ & $\mathbf{x}$ & $\begin{array}{c}\text { Nilai } \\
\mathbf{a}\end{array}$ & $\begin{array}{c}\text { Nilai } \\
\mathbf{b}\end{array}$ & $\begin{array}{r}\text { Peramalan } \\
\text { Kebutuhan }\end{array}$ \\
\hline Jan & 13 & $8.028,5$ & 456,5 & 10.641 \\
Feb & 14 & $8.028,5$ & 456,5 & 10.842 \\
Mar & 15 & $8.028,5$ & 456,5 & 11.043 \\
Apr & 16 & $8.028,5$ & 456,5 & 11.244 \\
Mei & 17 & $8.028,5$ & 456,5 & 11.446 \\
Jun & 18 & $8.028,5$ & 456,5 & 11.647 \\
Jul & 19 & $8.028,5$ & 456,5 & 11.848 \\
Agst & 20 & $8.028,5$ & 456,5 & 12.049 \\
Sept & 21 & $8.028,5$ & 456,5 & 12.250 \\
Okt & 22 & $8.028,5$ & 456,5 & 12.452 \\
Nov & 23 & $8.028,5$ & 456,5 & 12.653 \\
Des & 24 & $8.028,5$ & 456,5 & 12.854 \\
\hline Total & 0 & & & 140.969 \\
\hline
\end{tabular}

Berdasarkan Tabel 2.6 di atas diperoleh angka peramalan/prediksi kebutuhan obat Amlodipine 5mg/30 sebesar 140.969 tablet untuk Tahun 2016.

4. Simvastatin $10 \mathrm{mg}$

Tabel. 2.7 Perhtiungan nilai koefisien a dan b obat generik Simvastatin $10 \mathrm{mg}$

\begin{tabular}{llrrr}
\hline $\begin{array}{c}\text { Tahun } \\
\text { 2015 }\end{array}$ & $\mathbf{x}$ & $\begin{array}{c}\text { Pakai } \\
\mathbf{2 0 1 5}\end{array}$ & \multicolumn{1}{c}{$\mathbf{x i}^{\mathbf{2}}$} & \multicolumn{1}{c}{ xiyi } \\
\hline Jan & -11 & 6.708 & 121 & -73.778 \\
Feb & -9 & 7.093 & 81 & -63.837 \\
Mar & -7 & 7.124 & 49 & -49.868 \\
Apr & -5 & 7.744 & 25 & -38.720 \\
Mei & -3 & 8.096 & 9 & -24.288 \\
Jun & -1 & 8.747 & 1 & -8.747 \\
Jul & 1 & 6.589 & 1 & 6.589 \\
Agst & 3 & 7.585 & 9 & 22.755 \\
Sept & 5 & 9.398 & 25 & 46.990 \\
Okt & 7 & 6.950 & 49 & 48.650 \\
Nov & 9 & 7.108 & 81 & 63.972 \\
Des & 11 & 8.976 & 121 & 98.736 \\
\hline Total & 0 & 92.118 & 572 & 28.454 \\
\hline
\end{tabular}

$$
\begin{aligned}
\mathrm{a} & =\Sigma \mathrm{Y} / \mathrm{n} \\
& =92.118 / 12 \\
& =7.676,5 \\
\mathrm{~b} & =\Sigma \mathrm{xy} / \Sigma \mathrm{x}^{2} . \\
& =28.454 / 572
\end{aligned}
$$




$$
=49,74
$$

Nilai prediksi kebutuhan diperoleh dari rumus:

$\mathrm{Y}=\mathrm{a}+\mathrm{b}(\mathrm{x})$

Berikut hasil perhitungan kebutuhan obat generikSimvastatin 10 mgTahun 2015 di Rumah Sakit Islam Surabaya:

Tabel 2.8 Peramalan Kebutuhan Obat Simvastatin 10 mg Tahun 2016 di RS Islam Surabaya

\begin{tabular}{lccrr}
\hline $\begin{array}{c}\text { Tahun } \\
\text { 2016 }\end{array}$ & $\mathbf{x}$ & $\begin{array}{c}\text { Nilai } \\
\text { a }\end{array}$ & $\begin{array}{c}\text { Nilai } \\
\text { b }\end{array}$ & $\begin{array}{r}\text { Peramalan } \\
\text { Kebutuhan }\end{array}$ \\
\hline Jan & 13 & $7.676,5$ & 49,74 & 8.323 \\
Feb & 14 & $7.676,5$ & 49,74 & 8.373 \\
Mar & 15 & $7.676,5$ & 49,74 & 8.422 \\
Apr & 16 & $7.676,5$ & 49,74 & 8.472 \\
Mei & 17 & $7.676,5$ & 49,74 & 8.522 \\
Jun & 18 & $7.676,5$ & 49,74 & 8.572 \\
Jul & 19 & $7.676,5$ & 49,74 & 8.621 \\
Agst & 20 & $7.676,5$ & 49,74 & 8.671 \\
Sept & 21 & $7.676,5$ & 49,74 & 8.721 \\
Okt & 22 & $7.676,5$ & 49,74 & 8.771 \\
Nov & 23 & $7.676,5$ & 49,74 & 8.820 \\
Des & 24 & $7.676,5$ & 49,74 & 8.870 \\
\hline Total & 0 & & & 103.158 \\
\hline
\end{tabular}

Berdasarkan Tabel 2.8 di atas diperoleh angka peramalan/prediksi kebutuhan obat Simvastatin $10 \mathrm{mg}$ sebesar 103.158 tablet untuk Tahun 2016.

5. Glibenclamide

Tabel. 2.9Perhtiungan nilai koefisien a dan b obat generik Glibenclamide

\begin{tabular}{lrrrr}
\hline $\begin{array}{c}\text { Tahun } \\
\text { 2015 }\end{array}$ & \multicolumn{1}{c}{$\mathbf{x}$} & \multicolumn{1}{c}{$\begin{array}{c}\text { Pakai } \\
\mathbf{2 0 1 5}\end{array}$} & \multicolumn{1}{c}{$\mathbf{x i}^{\mathbf{2}}$} & \multicolumn{1}{c}{ xiyi } \\
\hline Jan & -11 & 6.862 & 121 & -75.482 \\
Feb & -9 & 7.676 & 81 & -69.084 \\
Mar & -7 & 8.531 & 49 & -59.717 \\
Apr & -5 & 9.081 & 25 & -45.405 \\
Mei & -3 & 8.090 & 9 & -24.270 \\
Jun & -1 & 7.434 & 1 & -7.434 \\
Jul & 1 & 4.657 & 1 & 4.657 \\
Agst & 3 & 6.764 & 9 & 20.292 \\
Sept & 5 & 6.716 & 25 & 33.580 \\
Okt & 7 & 7.715 & 49 & 54.005 \\
Nov & 9 & 6.761 & 81 & 60.849 \\
Des & 11 & 6.922 & 121 & 76.142 \\
\hline Total & 0 & 87.209 & 572 & -31.867 \\
\hline
\end{tabular}

$$
\begin{aligned}
\mathrm{a} & =\Sigma \mathrm{Y} / \mathrm{n} \\
& =87.209 / 12 \\
& =7.267,41
\end{aligned}
$$

$$
\begin{aligned}
\mathrm{b} & =\Sigma \mathrm{xy} / \Sigma \mathrm{x}^{2} . \\
& =-31.867 / 572 \\
& =-55,71
\end{aligned}
$$

Nilai prediksi kebutuhan diperoleh dari rumus:

$\mathrm{Y}=\mathrm{a}+\mathrm{b}(\mathrm{x})$

Berikut hasil perhitungan kebutuhan obat generik Glibenclamide Tahun 2015 di Rumah Sakit Islam Surabaya:

Tabel 2.10 Peramalan Kebutuhan Obat Glibenclamide Tahun 2016 di RS Islam Surabaya

\begin{tabular}{lcccr}
\hline $\begin{array}{c}\text { Tahun } \\
\text { 2016 }\end{array}$ & $\mathbf{x}$ & $\begin{array}{c}\text { Nilai } \\
\mathbf{a}\end{array}$ & $\begin{array}{c}\text { Nilai } \\
\mathbf{b}\end{array}$ & $\begin{array}{c}\text { Peramalan } \\
\text { Kebutuhan }\end{array}$ \\
\hline Jan & 13 & $7.267,4$ & $-55,7$ & 6.543 \\
Feb & 14 & $7.267,4$ & $-55,7$ & 6.487 \\
Mar & 15 & $7.267,4$ & $-55,7$ & 6.432 \\
Apr & 16 & $7.267,4$ & $-55,7$ & 6.376 \\
Mei & 17 & $7.267,4$ & $-55,7$ & 6.320 \\
Jun & 18 & $7.267,4$ & $-55,7$ & 6.265 \\
Jul & 19 & $7.267,4$ & $-55,7$ & 6.209 \\
Agst & 20 & $7.267,4$ & $-55,7$ & 6.153 \\
Sept & 21 & $7.267,4$ & $-55,7$ & 6.097 \\
Okt & 22 & $7.267,4$ & $-55,7$ & 6.042 \\
Nov & 23 & $7.267,4$ & $-55,7$ & 5.986 \\
Des & 24 & $7.267,4$ & $-55,7$ & 5.930 \\
\hline Total & 0 & & & 74.842 \\
\hline
\end{tabular}

Berdasarkan Tabel 2.10 di atas diperoleh angka peramalan/prediksi kebutuhan obat Glibenclamide sebesar 74.842 tablet untuk Tahun 2016.

Dari hasil peramalan kebutuhan 5 sampel obat, di atas disajikan perbedaan pemakaian Tahun 2015 dengan hasil peramalan pemakaian Tahun 2016 sebagai berikut:

Tabel 2.11 Perbedaan pemakain Tahun 2015 dan hasil peramalan pemakaian Tahun 2016 di RS Islam Surabaya

\begin{tabular}{llll}
\hline No & Nama Obat & $\begin{array}{c}\text { Pakai } \\
\mathbf{2 0 1 5}\end{array}$ & $\begin{array}{c}\text { Prediksi } \\
\mathbf{2 0 1 6}\end{array}$ \\
\hline 1 & $\begin{array}{l}\text { Metformin 500 } \\
\text { mg/ 100 }\end{array}$ & 408.258 & 509.613 \\
2 & $\begin{array}{l}\text { Amlodipine 10 } \\
\text { mg/ 30' }\end{array}$ & 119.170 & 124.719 \\
3 & $\begin{array}{l}\text { Amlodipine 5 } \\
\text { mg/ 30' }\end{array}$ & 96.307 & 140.969 \\
4 & $\begin{array}{l}\text { Simvastatin 10 } \\
\text { mg }\end{array}$ & 92.118 & 103.158 \\
5 & Glibenclami & 87.209 & 74.842 \\
\hline
\end{tabular}


de

Berdasarkan Tabel 2.11 di atas dapat dilihat perbedaan nilai pemakaian pada Tahun 2015 dengan nilai peramalan pemakaian Tahun 2016. Diprediksikan pemakaian obat Metformin 500mg/ 100, Amlodipine 10mg/ 30, Amlodipine 5mg/ 30, Simvastatin $10 \mathrm{mg}$ pada Tahun 2016 akan mengalami peningkatan pemakaian. Peningkatan pemakaian tersebut akan dipengaruhi oleh banyak faktor, diantaranya yang mungkin berpengaruh adalah angka kunjungan pasien yang semakin meningkat, dan prevalensi penyakit degenratif yang semakin meningkat. Obat Glibenclamide diprediksikan dari pemakaian Tahun 2015 ke pemakaian Tahun 2016 akan mengalami penuruan tingkat pemakaian.

\section{Pengendalian Persediaan}

Pelaksanaan pemesanan obat di Unit Farmasi Rumah Sakit Islam Surabaya belum melakukan perhitungan khusus untuk perencanaan maupun pengendalian. Jumlah pemesanan ditentukan berdasarkan pemakaian obat periode sebelumnya tanpa melakukan perhitungan dengan metode tertentu.

Jumlah stok minimum dan maksimum yang sesuai untuk persediaan obat agar tidak terjadi kekosongan maupun kelebihan stok obat, dapat digunakan metode MMSL (Minimum-Maximum Stock Level). Penentuan stock minimum dan maximum dapat dihitung dengan mengetahui lead time, stok pengaman dan periode pengadaan yang dilakukan untuk masing-masing item obat. Berdasarkan hasil wawancara dengan Kepala Unit Farmasi diperoleh hasil lead time untuk obat yang digunakan dalam sampel penelitian adalah 3 hari atau 0,1 bulan, sedangkan periode pengadaan untuk obatobat tersebut adalah 14 hari atau 0,5 bulan. Jumlah safety stock untuk masing-masing obat dapat dihitung dengan menggunakan rumus pemakaian perbulan dikalikan dengan lead time obat, hasil perhitungan tersebut disajikan pada tabel dibawah sebagai berikut:

Tabel 3.1 Hasil perhitungan safety stock obat

\begin{tabular}{|c|c|c|c|c|}
\hline No & Nama Obat & $\begin{array}{c}\text { Pakai } \\
\text { per } \\
\text { bulan }\end{array}$ & lt & SS \\
\hline 1 & $\begin{array}{l}\text { Metformin } 500 \\
\mathrm{mg} / 100\end{array}$ & 42.468 & 0,1 & 4.247 \\
\hline 2 & $\begin{array}{l}\text { Amlodipine } 10 \\
\mathrm{mg} / 30^{\prime}\end{array}$ & 10.394 & 0,1 & 1.040 \\
\hline 3 & $\begin{array}{l}\text { Amlodipine } 5 \\
\mathrm{mg} / 30^{\prime}\end{array}$ & 11.748 & 0,1 & 1.175 \\
\hline 4 & $\begin{array}{l}\text { Simvastatin } 10 \\
\mathrm{mg}\end{array}$ & 8.597 & 0,1 & 860 \\
\hline 5 & Glibenclamide & 6.237 & 0,1 & 624 \\
\hline
\end{tabular}

Berdasarkan Tabel 3.1 di atas atas dapat diketahui bahwa seluruh obat memiliki lead time yang sama, namun nilaisafety stock yang berbeda. Perbedaan nilai safety stock dipengaruhi oleh besarnya nilai ratarata pemakaian obat per bulan dari masing-masing jenis obat.

Setelah diketahui safety stock dari masingmasing obat, langkah selanjutnya adalah menghitung nilai stock minimum dan maksimum untuk mengetahui jumlah stok minimum dan maksimum yang sesuai untuk persediaan obat agar tidak terjadi kekosongan maupun kelebihan stok obat. Stok minimum ditentukan dari rata-rata pemakaian bulanan dikalikan dengan lead time ditambah dengan stok pengaman (safety stock). Sedangkan stok maksimum ditentukan dari jumlah stok minimum ditambahkan dengan waktu pengadaan (periode pengadaan) dikalikan dengan rata-rata pemakaian. Dapat dirumuskan sebagai berikut:

Stok minimum $=($ LT $\times$ CA $)+S S$

Stok maksimum $=$ Smin $+(\mathrm{PP} \times \mathrm{CA})$

Periode pengadaan untuk masing-masing obat diketahui sebesar 14 hari atau 0.5 bulan.Jumlah Pemesanan diperoleh dari jumlah stok maksimum dikurangkan dengan jumlah stok mimumum.Hasil perhitungan stok minimum dan stok 
maksimum obat generik disajikan dalam tabel sebagai berikut:

Tabel 3.2 Hasil perhitungan stok minimum dan stok maksimum obat generik di RS Islam Surabaya Tahun 2016

\begin{tabular}{|c|c|c|c|c|}
\hline No & Nama Obat & $\begin{array}{l}\text { Stok } \\
\text { Min }\end{array}$ & $\begin{array}{l}\text { Stok } \\
\text { Max }\end{array}$ & $\begin{array}{c}\text { Jumlah } \\
\text { Pesan }\end{array}$ \\
\hline 1 & $\begin{array}{l}\text { Metformin } \\
500 \mathrm{mg} / 100\end{array}$ & 8.494 & 29.728 & 21.235 \\
\hline 2 & $\begin{array}{l}\text { Amlodipine } \\
10 \mathrm{mg} / 30^{\prime}\end{array}$ & 2.082 & 7.277 & 5.198 \\
\hline 3 & $\begin{array}{l}\text { Amlodipine } \\
5 \mathrm{mg} / 30^{\prime}\end{array}$ & 2.350 & 8.244 & 5.875 \\
\hline 4 & $\begin{array}{l}\text { Simvastatin } \\
10 \mathrm{mg}\end{array}$ & 1.720 & 6.019 & 4.300 \\
\hline 5 & $\begin{array}{l}\text { Glibenclami } \\
\text { de }\end{array}$ & 1.248 & 4.367 & 3.120 \\
\hline
\end{tabular}

Berdasarkan Tabel 3.2 di atas diperoleh hasil stok minimum dan stok maksimum yang harus disediakan untuk masingmasing obat generik yang diteliti agar stoknya tidak berlebih maupun mengalami kekosongan stok.

Apabila persediaan obat Metformin 500 $\mathrm{mg} / 100$ di depo farmasi telah mencapai level minimum yaitu 8.494 tablet, maka harus dilakukan pemesanan kembali, dengan jumlah pemesanan obat sebesar 21.235 tablet agar tidak terjadi kekosongan stok obat.

Apabila persediaan obat Amlodipine 10 $\mathrm{mg} / 30$ ' di depo farmasi telah mencapai level minimum yaitu 2.082 tablet, maka harus dilakukan pemesanan kembali, dengan jumlah pemesanan obat sebesar 5.198 tablet agar tidak terjadi kekosongan stok obat.

Apabila persediaan obat Amlodipine $5 \mathrm{mg} /$ 30' di depo farmasi telah mencapai level minimum yaitu 2.350 tablet, maka harus dilakukan pemesanan kembali, dengan jumlah pemesanan obat sebesar 5.875 tablet agar tidak terjadi kekosongan stok obat.

Apabila persediaan obat Simvastatin 10 $\mathrm{mg}$ di depo farmasi telah mencapai level minimum yaitu 1.720 tablet, maka harus dilakukan pemesanan kembali, dengan jumlah pemesanan obat sebesar 4.300 tablet agar tidak terjadi kekosongan stok obat.

Apabila persediaan obat Glibenclamide di depo farmasi telah mencapai level minimum yaitu 1.248 tablet, maka harus dilakukan pemesanan kembali, dengan jumlah pemesanan obat sebesar 4.367 tablet agar tidak terjadi kekosongan stok obat.

Jumlah pemesanan kembali dilakukan pada saat persediaan mencapai kondisi minimal (level minimum), hal ini dikarenakan persediaan pada level minimal memang disediakan untuk memenuhi kebutuhan selama masa tenggang (lead time). Jumlah pemesanan kembali dilakukan selama satu periode pengadaan.Hal ini dikarenakan pada metode MMSL (Minimum-Maximum Stock Level), persediaan obat tidak boleh melebihi dari stok minimal dan tidak boleh melebihi dari stok maksimal.Jumlah pemesanan obat ini berlaku selama satu periode pengadaan dari masing-masing jenis obat.

\section{SIMPULAN}

Unit Farmasi di Rumah Sakit Islam Surabaya belum menggunakan metode tertentu dalam melakukan perencanaan kebutuhan obat.Kebutuhan obat hanya diperkirakan berdasarkan penggunaan obat pada periode sebelumnya, tanpa melakukan perhitungan dengan metode peramalan tertentu untuk mengetahui kebutuhan obat yang sesuai, sehingga kejadian stockout obat belum bisa dihindari.Unit Farmasi di Rumah Sakit Islam Surabaya belum menggunakan metode tertentu dalam melakukan pengendalian persediaan obat.

Berdasarkan klasifikasi obat dengan menggunakan analisis tingkat pemakaian dari 148 jenis obat yang dianalisis, didapatkan hasil 28 jenis obat termasuk dalam kategori fast moving. Peramalan kebutuhan obat generik dengan menggunakan metode least square di Unit Farmasi Rumah Sakit Islam Surabaya 
untuk Tahun 2016 didapatkan hasil sebagai berikut, Metformin $500 \mathrm{mg} / 100$ sebesar 509.613 tablet, Amlodipine $10 \mathrm{mg} / 30$ sebesar 124.719 tablet, Amlodipine 5mg/30 sebesar 140.969 tablet, Simvastatin $10 \mathrm{mg}$ sebesar 103.158 tablet, Glibenclamide sebesar 74.842 tablet.

Pengendalian persediaan dengan metode MMSL diperoleh hasil stok minimum dan maksimum obat generik di Unit Farmasi Rumah Sakit Islam Surabaya didapatkan hasil sebagai berikut, stok minimum Metformin $500 \mathrm{mg} / 100$ sebesar 8.494 tablet dan stok maksimum sebesar 29.728tablet, stok minimum Amlodipine $10 \mathrm{mg} / 30$ sebesar2.082 tablet dan stok maksimum sebesar 7.277 tablet, stok minimum Amlodipine 5mg/30 sebesar 2.350tablet dan stok maksimum sebesar 8.244 tablet, stok minimum Simvastatin $10 \mathrm{mg}$ sebesar 1.720tablet dan stok maksimum sebesar 6019 tablet, stok minimum Glibenclamide sebesar 1.248tablet dan stok maksium sebesar 4.367.

Jumlah pemesanan kembali obat generik kategori fast moving dengan metode MMSL di Unit Farnasi Rumah Sakit Islam Surabaya dalam penelitian ini yaitu :Metformin $500 \quad \mathrm{mg} / 100$ jumlah pemesanan obat sebesar 21.235 tablet, Amlodipine $10 \mathrm{mg} / 30$ ' jumlah pemesanan obat sebesar 5.198 tablet, Amlodipine 5 mg/ 30' jumlah pemesanan obat sebesar 5.875 tablet, Simvastatin $10 \mathrm{mg}$ jumlah pemesanan obat sebesar 4.300 tablet, Glibenclamidejumlah pemesanan obat sebesar 4.367 tablet

\section{SARAN}

1. Adanya kejadian stockout obat pada jenis obat generik, mengharuskan Kepala Unit Farmasi Rumah Sakit Islam Surabaya untuk melakukan perencanaan lebih baik dengan melakukan analisis berdasarkan tingkat pemakaian, dan melakukan perencanaan dengan melakukan perhitungan kebutuhan menggunakan metode peramalan yang disesuaikan dengan kondisi rumah sakit, dapat menggunakan metode rata-rata, least square, rata-rata kenaikan presentase, dan moving average.

2. Ketepatan forecasting obat sangat dipengaruhi oleh data historical dari pemakaian obat tahun-tahun sebelumnya, oleh karena itu pihak unit farmasi harus melakukan pengawasan terhadap pencatatan pemakaian obat dengan baik. Sistem pencatatan obat yang dilakukan dengan komputer harus dapat diolah dengan baik agar data yang ada dapat digunakan untuk menghasilkan informasi yang baik, oleh karena itu disarankan sistem informasi manajemen yang ada di Unit Farmasi untuk diupgrade lebih baik.

3. Kejadian stockout juga dapat diminimalisir dengan melakukan pengendalian persediaan, metode pengendalian persediaan disarankan dapat menggunakan metode MMSL. Akan tetapi metode ini memiliki kekurangan dan kelebihan. Kelebihannya adalah kemungkinan terjadi stokcout adalah kecil. Sedangkan kekurangnnya adalah tidak dapat memperoleh harga pembelian obat yang efisien. Sehingga dengan adanya keterbatasan pada penelitian ini, maka perlu diadakan penelitian lebih lanjut mengenai perencanaan dan pengendalian persediaan menggunakan analisis yang berbeda, sebagai tambahan informasi bagi instansi terkait.

\section{DAFTAR PUSTAKA}

Aditama, T.Y. 2003.Manajemen Administrasi Rumah Sakit. Jakarta: Universitas Indonesia Press.

Assauri, S. (1984).Teknik dan Metode Peramalan. Jakarta: Fakultas Ekonomi Universitas Indonesia. 
Departemen Kesehatan Republik Indonesia.2003. Pedoman Pengelolaan Obat Publik dan Perbekalan Kesehatan di Puskesmas. Jakarta

Gazali, S.Y. 2002.Modul Manajemen Logistik "Pengendalian persediaan". FKM UI 2002

Rambe, M.I.F. 2014. Perancangan Aplikasi Peramalan Persediaan ObatObatan Menggunakan Metode Least Square (Studi Kasus : Apotek Mutiara Hati). Pelita Informatika Budi Darma, Volume : VI, Nomor 1, Maret 2014. tersedia di: <http://www.pelitainformatika.com/berkas/jurnal/9.\%20ihsan \%20fauzi.pdf.>[diakses tanggal 10 juni 2016]

Rangkuti, F. 2004. Manajemen Persediaan, Aplikasi di Bidang Bisnis. Jakarta: Raja Grafindo Persada.

Seto, S. 2001. Manajemen Apoteker, untuk pengelola : Apotek, Farmasi Rumah Sakit, Pedagang Besar Farmasi, Industri Farmasi. Surabaya: Airlangga University Press.

Setyowati, J.D.\& Purnomo, W. 2004.Analisis Kebutuhan Obat Dengan Metode Konsumsi Dalam Rangka Memenuhi Kebutuhan Obat Di Kota Kediri. Jurnal Administrasi Kebijakan Kesehatan. Volume (02): 188-195.

Suciati, S. \& Adisasmito, W. 2006.Analisis Perencanaan Obat Berdasarkan ABC Indeks Kritis di Instalasi Farmasi. Jurnal Manajemen Pelayanan Kesehatan, 09: 19-26 